\title{
A compreensão de grupos nominais em inglês como LE
}

Simone Correia Tostes

Universidade Federal do Rio de Janeiro

O processo de leitura envolve operações cognitivas ainda pouco pesquisadas. No caso da leitura em língua estrangeira, aprendizes tendem a lançar mão de princípios de sua L1. Essa transferência pode levar a problemas de compreensão da LE. Neste estudo, verificamos a ocorrência desses problemas de leitura em grupos nominais, que, na língua inglesa, apresentam um princípio diferente da L1 português, com seu núcleo figurando como último elemento. Os leitores de LE demonstram aplicar o parâmetro da L1 português, que apresenta o núcleo como primeiro elemento do sintagma, em escala maior nos níveis incipientes, chegando a níveis menores em leitores de nível avançado de proficiência.

The reading process involves cognitive operations still little researched. In the case of reading in a foreign language, learners tend to apply L1 principles. This transfer may cause problems in the comprehension of an FL. In this study, we have checked the occurrence of reading problems related to nominal groups that, in English, present a principle different from the L1 Portuguese, with a nuclear element in the last position. Readers of English as an FL have applied the parameter of their L1 Portuguese, which presents a nuclear element as the first element in the group, in greater levels in beginners, reaching lower levels in readers in advanced levels of proficiency.

\section{Introdução}

Há muito convencionou-se que a definição mais geral de leitura seria a "transformação de 'rabiscos' em idéias" (COSCARELLI, 2002, p. 8), embora seja essa uma visão bastante reducionista do complexo processo da leitura. Além de decodificar os "rabiscos", o leitor deve ser capaz de realizar atividades de atribuição de significados aos sinais lingüísticos lançados sobre uma superfície, que pode ser desde a pedra, passando pela folha de um livro ou caderno, até chegar à tela do computador, que traz uma nova definição de página, que, dessa vez, pode ser recuperada ao se transformarem bites em sinais gráficos através de programas de computador. 
Coscarelli (op. cit.) aponta ser a visão da leitura como processo indivisível uma das dificuldades que enfrentam os professores que ensinam a leitura a seus alunos. Segundo a autora, o primeiro passo para se alcançar um sucesso maior no ensino/aprendizagem da leitura seria subdividi-la em duas partes maiores: a primeira englobaria processos que lidam com a forma lingüística; a outra abrangeria os procedimentos envolvidos na atribuição de significado.

Essas duas partes maiores podem ainda ser subdivididas: $O$ processamento da forma, ou decodificação, pode ser fragmentado em processamento lexical e processamento sintático; o processamento do significado pode ser tripartido - a construção da coerência local, a construção da coerência temática e a construção da coerência externa.

São ainda relacionados os fatores que influenciam o processamento sintático, dentre os quais destacamos (1) a canonicidade e a complexidade sintática da sentença e (2) a familiaridade do leitor com a estrutura sintática da frase.

Esses mesmos processos ocorrem quando se trata do processamento da leitura em língua estrangeira (LE, daqui por diante). O leitor aprendiz de uma LE tem que ser capaz de fazer a decodificação lexical e sintática do texto, bem como ser competente em atribuir significado local, temático e externo ao texto lido.

Por se tratar de uma LE, ${ }^{1}$ o aprendiz tem acesso aos princípios e parâmetros instanciados na L1. Dessa forma, ao aprender uma segunda língua, lançaria mão dessas estratégias para a solução de problemas na LE (cf. SCHACHTER, 1989).

Os pesquisadores de universais de aquisição de segunda língua partem do princípio de que a aprendizagem de parâmetros semelhantes na L1 e na LE é facilitada. Em contrapartida, as estruturas mais marcadas seriam adquiridas mais tardiamente, porque exigem um grau de

\footnotetext{
${ }^{1}$ A distinção entre os conceitos de L2 e LE é comumente realizada para diferenciar uma aquisição de língua com papel social e institucional na comunidade e a aprendizagem em contextos de ensino, respectivamente (cf. Ellis, 1996). Neste trabalho, utilizamos o termo L2 para nos referirmos à aquisição de uma segunda língua, num sentido amplo e neutro do termo, enquanto o termo LE é utilizado para nos referirmos à aprendizagem em contextos de ensino-aprendizagem de línguas estrangeiras.
} 
processamento mais alto. Conseqüentemente, as teorias de aquisição da linguagem "(...) prevêem que aquilo que é mais marcado, inter e intralingüisticamente, será adquirido depois do que é não marcado" (LEIRIA, 1996, p. 80).

Estudos como o de França (1997) já apontaram a contaminação por L1 de mecanismos de aquisição de L2, sendo facilmente discriminável o desempenho de falantes não-nativos. Segundo essa autora, "qualquer análise rápida da produção de falantes adultos de L2 pode comprovar algum nível de contaminação por L1, demonstrando que a base de L2 é um sistema já marcado por outra língua" (Id., p. 45). Da mesma forma, Fernández (1999) justifica o insucesso de aprendizes adultos de uma segunda língua pelo fato de suas estratégias de processamento serem influenciadas por outras específicas da L1.

Nesta pesquisa, procuramos verificar se a contaminação por parâmetros da L1 português influenciaria a compreensão através de leitura de grupos nominais em inglês. A experiência como professora de Inglês em escolas da rede oficial de ensino demonstra que, ao utilizar-se de princípios da sua L1, o aprendiz tende ao insucesso no que concerne à compreensão de sintagmas nominais em inglês. Uma das diferenças básicas entre as duas línguas consiste no fato de o núcleo do SN na LE inglês ser colocado na última posição do sintagma (cf. COLLINS COBUILD, 1990), o que não é comum na língua portuguesa, em que a colocação do elemento nuclear no fim do sintagma é extremamente marcada, sendo portanto bastante incomum nessa língua, com exceção de expressões cristalizadas, ou em expressões com alto grau de subjetividade e/ou poéticas.

Na literatura lingüística disponível, existem indicações de que a língua portuguesa seja uma língua "orientada" para a esquerda. Dessa forma, flexões de número tendem a ocorrer antepostas ao núcleo do sintagma (cf. SCHERRE, 1996) - as coisa; de maneira semelhante, a negação nessa língua realiza-se antes do verbo (cf. RONCARATI, 1997) - nãofoi, e os verbos da voz passiva sintética são raramente conjugados no plural (cf. Vende-se casas), uma vez que, geralmente, não se reconhece a informação de número que o sujeito posposto plural oferece.

O mesmo processo não coincide com a língua inglesa, que coloca as marcas de plural, por exemplo, apenas no núcleo (substantivo ou pronome) do sintagma. Assim, o aprendiz de LE inglês tende a procurar 
marcas de plural, bem como núcleos do sintagma nos primeiros elementos; em contrapartida, essas marcas localizam-se no final do sintagma nominal, conforme demonstram os exemplos (1) e (2) a seguir:

1. According togang enforcement officers, Oregon will be the next Los Angeles in the year 2002. (http://pythia.uoregon.edu/ cyberj/ gangs.htm)

2. The University Counselling and Guidance Service offers help to students with financial problems. (University of Wolverhampton Catalogue)

No exemplo (1) verifica-se a marca de plural $s$ apenas no terceiro elemento do sintagma - officers -, pois gang e enforcement são dois substantivos adjetivados através de sua colocação anterior ao núcleo do sintagma. O exemplo (2) traz um sintagma nominal com seis elementos, dos quais o último - Service - constitui-se no núcleo do grupo.

A dificuldade que os sintagmas nominais em inglês provocam pode estar associada ao critério da marcação discursiva, elaborado por Talmy Givón (1995). Segundo esse autor,

(...) a marcação pressupõe a noção de complexidade formal, segundo a qual o marcado é estruturalmente mais complexo e o não-marcado mais simples. Mas aspectos outros além da complexidade formal são igualmente centrais para nossa compreensão de marcação. Primeiramente, localiza-se a questão da freqüência de distribuição, onde tipicamente a categoria marcada é menos freqüente, enquanto a não-marcada é mais freqüente. (p. 25).

Além disso, Givón (1995) acrescenta que o critério da marcação depende do contexto:

A mesma estrutura pode ser marcada em um contexto e não marcada em um outro. (...)

Uma importante conseqüência lógica da marcação é que explicações consistentes da marcação devem ser específicas de um domínio. (p. 27).

Dessa forma, enquanto para falantes de L1 inglês, a ordem do sintagma nominal é não-marcada, onde se prevêem elementos adjetivos antes dos núcleos substantivos, essa ordenação tende a ser marcada num contexto de aprendizagem de LE inglês que envolve falantes de português, em que essa ordenação é inversa, com substantivos como núcleos do sintagma nominal localizados à esquerda do mesmo. 
Callou e Serra (2003) comparam a aparente liberdade da colocação do adjetivo em português e espanhol, em contraste com o inglês:

Em línguas como o português e o espanhol a posição que o adjetivo ocupa no SN é mais "livre", se comparadas ao inglês, por exemplo, que tem uma ordem bastante rígida para a colocação dos adjetivos, sempre antepostos ao nome. (p. 194).

O estudo de Callou e Serra (op. cit.) também procurou correlacionar a colocação do adjetivo a seu caráter discursivo, visando a confirmar a hipótese de que adjetivos mais pesados (aqueles que possuem uma dimensão maior em relação ao substantivo) tendem a aparecer em posição pós-nuclear. Estudos longitudinais da língua portuguesa já demonstraram que o posicionamento dos adjetivos antes do núcleo do $\mathrm{SN}$ foi se tornando cada vez mais raro.

Este estudo visa a verificar o nível de compreensão de grupos nominais em inglês como língua estrangeira por alunos brasileiros submetidos à aprendizagem desse idioma e distribuídos por níveis de proficiência. Nossa hipótese é a de que a relação entre o nível de proficiência de aprendizes e os problemas de compreensão de SNs em LE inglês seja inversamente proporcional, isto é, quanto mais proficientes na LE, menos problemas de compreensão dos SNs existem e, opostamente, quanto mais incipientes na aprendizagem da LE inglês, mais haverá problemas de compreensão dos SNs em LE inglês.

\section{Metodologia de pesquisa}

Primeiramente, foi elaborado um teste de dez frases (cf. Anexo I), das quais os alunos entrevistados deveriam traduzir os enunciados negritados. Esses enunciados variavam nas funções de sujeito, objeto ou complemento de uma preposição, de acordo com a função sintática que exerciam na oração.

O teste compunha-se de três partes: (1) na primeira, o aluno deveria responder sobre a duração de seus estudos de inglês como LE, seja em cursos de inglês, em escolas ou em instituições de ensino estrangeiras; nessa parte, o aluno também deveria fazer uma avaliação de seu nível de conhecimento do idioma e se classificar em um dos níveis apresentados no questionário (básico, intermediário ou avançado); (2) em seguida, os alunos passavam a apresentar as traduções para os 
sintagmas assinalados em cada uma das frases; (3) na terceira etapa do teste, o aluno deveria fazer uma avaliação e assinalar com um (ü) o item que considerou mais fácil, e com um (X) o item cuja tradução considerou mais difícil.

Esses testes foram aplicados em turmas de pré-vestibular de um colégio da rede pública federal do Rio de Janeiro. Os alunos não foram obrigados a responder aos questionários; apenas lhes foi solicitada a colaboração para uma pesquisa que estava sendo realizada sobre a leitura dos alunos. Todos os alunos concordaram em responder ao teste, tendo sido alertado que seu objetivo era apenas diagnóstico e em nada influenciaria o desempenho final do aluno no ano escolar em curso.

Após a etapa inicial de aplicação dos questionários, foi feita a tabulação das respostas apresentadas pelos alunos. Na etapa de tabulação, os entrevistados foram subdivididos em três níveis, levandose em conta as respostas apresentadas na primeira parte do teste. Em geral, nessa escola, havia três tipos de clientela: (a) alunos que estudaram inglês apenas em escolas; (b) alunos que estudaram inglês em cursos livres e em escolas e (c) alunos que estudaram inglês em escolas estrangeiras, em cursos livres e em escolas brasileiras.

Para classificar o aluno no nível de fluência mais adequado de acordo com sua experiência como aprendiz de inglês como língua estrangeira, foi considerada a situação de maior duração, isto é, se o aluno estudou um ano de inglês em curso livre e está no nível iniciante, mas cursou cinco anos em colégios, sendo nivelado no estágio intermediário, por exemplo, foi considerado como aprendiz de nível intermediário, pois a segunda situação teve maior duração.

Dessa forma, do universo de alunos pesquisados na $3^{\text {a }}$ Série do Ensino Médio daquela escola, existiram 12 alunos classificados no nível Iniciante, 24 alunos no nível Intermediário e 22 alunos no nível Avançado de aprendizagem do idioma. O ponto de corte entre os níveis iniciante e intermediário foi a duração de três anos de estudos do idioma inglês, que quase invariavelmente coincidiu com o autonivelamento do aluno no nível Intermediário. A classificação dos entrevistados no nível Avançado em geral ocorreu para alunos com quatro anos ou mais de estudo continuado de inglês em diversas situações, que, segundo os alunos, classificavam-nos no nível Avançado. 
Após a etapa de tabulação dos testes, em que os entrevistados foram divididos de acordo com sua proficiência no idioma, passamos à tabulação das respostas propriamente ditas. Nessa fase, deparamonos com alguns casos em que o aluno ora acertava totalmente a tradução, ora traduzia parcialmente o enunciado. Para fins deste estudo, resolvemos sinalizar na tabulação das respostas três tipos de situação: (i) com ü aqueles enunciados traduzidos corretamente em sua totalidade; (ii) com $\mathrm{N}$ e um algarismo para os enunciados nos quais o aluno acertou apenas o núcleo do sintagma e apresentou um ou mais elementos traduzidos incorretamente; (iii) com $\mathrm{X}$ aquele sintagma traduzido incorretamente por completo. Assim, pudemos afinar um pouco mais nossa análise, em que se considera como uma das dificuldades principais da leitura em LE inglês a identificação do núcleo do SN.

Após a tabulação das respostas dos alunos, passamos à fase seguinte - a subdivisão dos enunciados em fáceis e difíceis, de acordo com a extensão do sintagma nominal, a transparência fônica dos elementos do SN e a complexidade vocabular dos SNs. Assim, destacamos para nossa análise sete frases que classificamos como: MF (mais fáceis) - 3 - e MD (mais difíceis) - 4. Os enunciados mais fáceis foram aqueles em que havia a inversão adjetivo-nome, própria dos SNs da língua inglesa. Como a língua portuguesa apresenta essa inversão, muitas vezes com alteração do significado do adjetivo, antevimos que esses enunciados, em princípio, não apresentariam grande dificuldade para a compreensão.

Moura Neves (2000) apontou uma diferença no comportamento das duas grandes subclasses de adjetivos, os qualificadores e os classificadores. Estes podem ser pospostos, posição não marcada, ou antepostos, posição marcada, comum em textos literários. À anteposição confere-se um aspecto de subjetividade, ou a ocorrência de uma cristalização, como atestado em pátrio poder, por exemplo.

Os enunciados considerados mais difíceis, por sua vez, além de apresentarem mais de dois elementos, por vezes não remetiam a vocábulos da L1 do aprendiz. Além disso, os adjetivos da língua inglesa são, por vezes, substantivos adjetivados. Estes não apresentam nenhum traço morfofonológico de adjetivo, sendo identificados como tal apenas por sua posição no SN. 


\section{Resultados}

A compreensão dos enunciados nos três níveis apresentou uma distribuição conforme prevista na nossa hipótese inicial. De forma geral, os enunciados mais "pesados" (isto é, aqueles que possuem um peso informacional maior, com dois ou três elementos antepostos ao núcleo) constituem uma dificuldade a mais para os aprendizes dos níveis iniciante e intermediário, em comparação com o nível avançado. Ao compararmos os gráficos, chegamos à conclusão de que os itens que apresentaram maior dificuldade para a compreensão foram os de números (1) e (7). Além de ser considerado um SN pesado (com quatro elementos), o Enunciado 1 dá "pistas falsas" ao leitor aprendiz. É o caso, por exemplo, do vocábulo cold, que pode ser entendido tanto como um resfriado, como pelo adjetivo frio. A presença desse vocábulo posposto ao artigo indefinido induziu à má compreensão, pois os alunos traduziram como resfriado, o que comprometeu o entendimento do SN como um todo.

Enunciado 1

A cold, sickening feeling came over me.

Tradução: Uma sensação de frio, enjoativa chegou até mim.

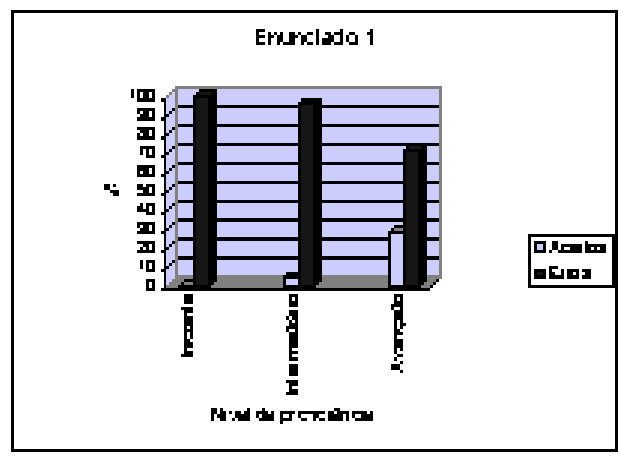

Vale ressaltar que, no Enunciado 1, 92\% dos entrevistados dos níveis iniciante e intermediário não conseguiram identificar o núcleo do SN (cf. Seção Identificação do núcleo do SN), percentual que continuou alto no nível avançado - 68\%. A outra dedução errônea que os aprendizes fazem é a de que a forma verbal de gerúndio (verbo + ing) é sempre traduzida como forma nominal. 


\section{Enunciado 7}

It has a much cheaper price tag.

Tradução: Ele(a) tem uma etiqueta de preço muito mais barato.

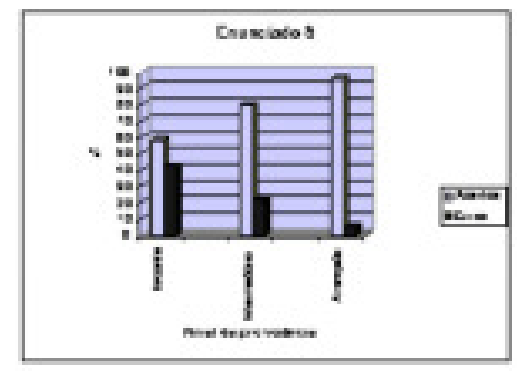

A análise dos resultados do Enunciado 7 também demonstrou que os alunos nivelados em iniciante e intermediário apresentaram grande dificuldade em identificar o núcleo do $\mathrm{SN}-75 \%$-, percentual que diminuiu no nível avançado - 48\%. Além de ser um enunciado pesado, com cinco elementos, o SN apresenta o vocábulo price como adjetivo, sem qualquer alteração mórfica da forma price como substantivo.

Apontamos como dificuldade a mais, não prevista inicialmente pela pesquisa, a existência de sinais de pontuação, como no Enunciado 1, em que a presença da vírgula separando os adjetivos do SN fez com que os alunos identificassem dois "núcleos" no mesmo SN - colde feeling. Apesar de notarmos uma discrepância ao atribuírem esses significados a esses supostos núcleos, entendemos que isso possa ser decorrente do recorte feito em textos autênticos, de onde foram retirados todos os enunciados, apresentados todos sem o contexto ao qual pertencem.

Enunciado 8

Two spacewalking astronauts fixed broken equipment tonight.

Tradução: Dois espaçonautas consertaram equipamento quebrado esta noite.

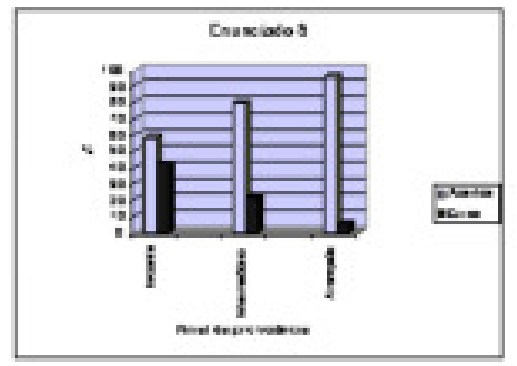


Os Enunciados (8), (9) e (10) foram classificados entre os mais fáceis. E apresentaram altos níveis de compreensão por parte dos aprendizes, desde o nível iniciante (acima de 50\%) até atingirem mais de $90 \%$ dos acertos no nível avançado. Os Enunciados 9 e 10, apesar de demonstrarem um crescimento na compreensão nos níveis intermediário e avançado, apresentaram uma distribuição curiosa. Em ambos, o nível intermediário aparece com percentuais mais altos de acertos. Isso talvez seja justificado por uma estratégia de leitura que "não deu certo" por parte dos leitores avançados, pois ambos apresentam adjetivos que evocam na mente do aprendiz palavras cognatas em sua L1. É esse o caso de surgical e exaggerated, que aparecem como qualificadores, e não como verbos (surgiram e exageraram, respectivamente).

Enunciado 9

Free of surgical complications that may affect other methods, the patch delivers hormones directly through the skin.

Tradução: Livre de complicações cirúrgicas que possam afetar outros métodos, o adesivo passa hormônios diretamente através da pele.

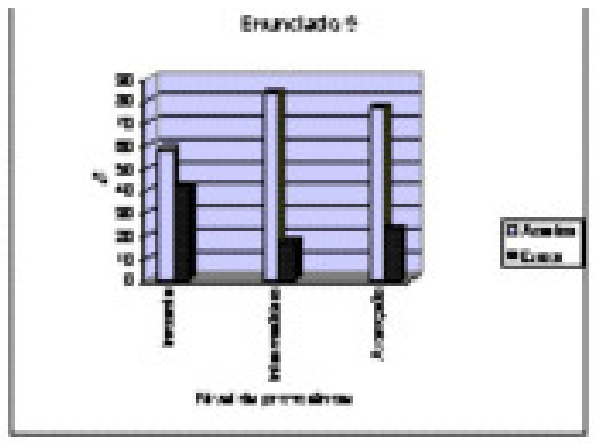




\section{Enunciado 10}

Recent decades were characterized by an exaggerated sense of the nobility of untutored behavior.

Tradução: As décadas recentes foram caracterizadas por um senso exagerado da nobreza do comportamento não orientado.

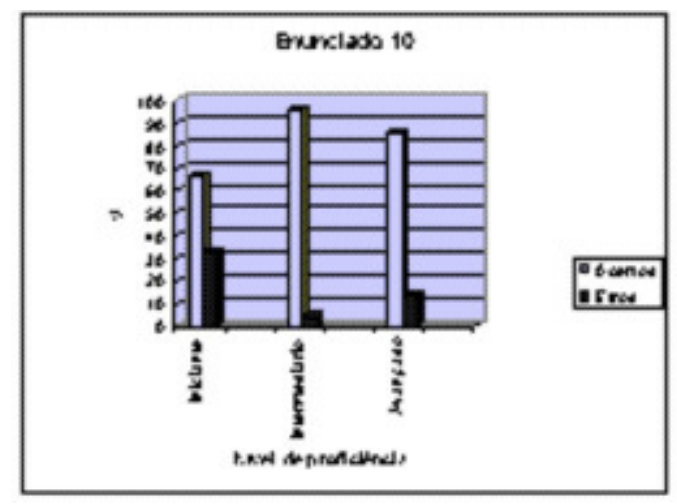

Esses percentuais podem ser contrastados com os resultados verificados na compreensão do Enunciado 8 , em que broken não remete a essa correspondência com a L1 do aprendiz.

\section{Conclusão}

O experimento para verificar a compreensão de aprendizes de LE inglês comprovou nossas hipóteses iniciais de que os SNs constituem uma dificuldade grande para os estudantes, que aplicam princípios da L1 para a solução de problemas de compreensão na LE. Como esses princípios não se aplicam no que concerne à organização do SN, que preconiza a colocação do núcleo do SN em inglês como último elemento do sintagma, diferentemente do que ocorre com o núcleo de grupos nominais em português, essa generalização por parte do aprendiz de LE inglês dificulta a compreensão de sintagmas nominais em LE.

Outra observação que merece relevância é o peso dos SNs; SNs mais "pesados" (com três ou mais elementos) exigem mais trabalho de processamento por parte do aprendiz, o que acarreta uma quantidade de erros significativa, desde os níveis mais incipientes até o nível mais avançado de proficiência. Os SNs mais "leves" (com apenas dois elementos - adjetivo + núcleo), apesar de apresentarem a "inversão" adjetivo- 
substantivo, que ocorre somente em situações excepcionais da L1 do aprendiz, apresentam menos dificuldade para a compreensão dos alunos.

Destacamos, por último, a transparência morfológica dos adjetivos na L1 dos alunos, em contraste com a inexistência de traços morfofonêmicos que salientem a mudança da função de adjetivo para substantivo, na língua inglesa. A inexistência dessas "pistas" dificultam em muito a atribuição de significados apropriados aos grupos nominais. De maneira semelhante, se o aluno elabora uma "falsa hipótese", atribuindo significados semelhantes na LE apenas pela semelhança gráfica (falso cognato), a compreensão fica seriamente comprometida, mesmo em níveis avançados de proficiência na LE.

Os achados desta pesquisa são ponto de partida para outros estudos relacionados à aplicação de princípios e parâmetros da L1 para a aprendizagem de LE.

\section{Referências Bibliográficas}

CALLOU, D.; SERRA, C. A variação na ordem dos adjetivos nos últimos quatro séculos. In: RONCARATI, C.; ABRAÇADO, J. (Org.) Português Brasileiro. Contato lingüístico, heterogeneidade e história. Rio de Janeiro: Ed. Viveiros de Castro, 2003.

COSCARELLI, C. V. Entendendo a leitura. In: NARO, A. J. et alii (Ed.) Revista de Estudos da Linguagem, Belo Horizonte, v. 10, n. 1, jan./jun. 2002.

ELLIS, R. The study of Second Language Acquisition. Hong Kong: OUP, 1996.

FERNÁNDEZ, E. M. Processing strategies in second language acquisition: some preliminary results. In: KLEIN, E. C.; MARTOHARDJONO, G. (Ed.) The development of second language grammars: a generative approach. Amsterdan: John Benjamins, 1999.

FRANÇA, A. I. Comparação entre a aquisição de português e inglês como L2. In: COUTO, H. H. do (Org.). Papia. Brasília: Universidade de Brasília, 1997.

GIVÓN, T. Functionalism and Grammar. Philadelphia: John Benjamins Publishing Company, 1995. 486p.

LEIRIA, I. Aquisição de língua não-materna. Um exemplo: o aspecto verbal. In: FARIA, I. H.; PEDRO, E. R.; DUARTE, I.; GOUVEIA, C. A. M. Introdução à lingüistica geral e portuguesa. Lisboa: Caminho, 1996. 
MOURA NEVES, M. H. Gramática de usos do português. São Paulo: UNESP, 2000.

RONCARATI, Cláudia. Ciclos aquisitivos da negação. In: RONCARATI, C.; MOLlICA, M.C.M. (Org.). Variação e Aquisição. Rio de Janeiro: Tempo Brasileiro, 1997.

SCHACHTER, J. Testing a proposal Universal. In: GASS, S.; SCHACHTER, J. (Org.). 1989, p. 73-88. 


\section{Anexo 1}

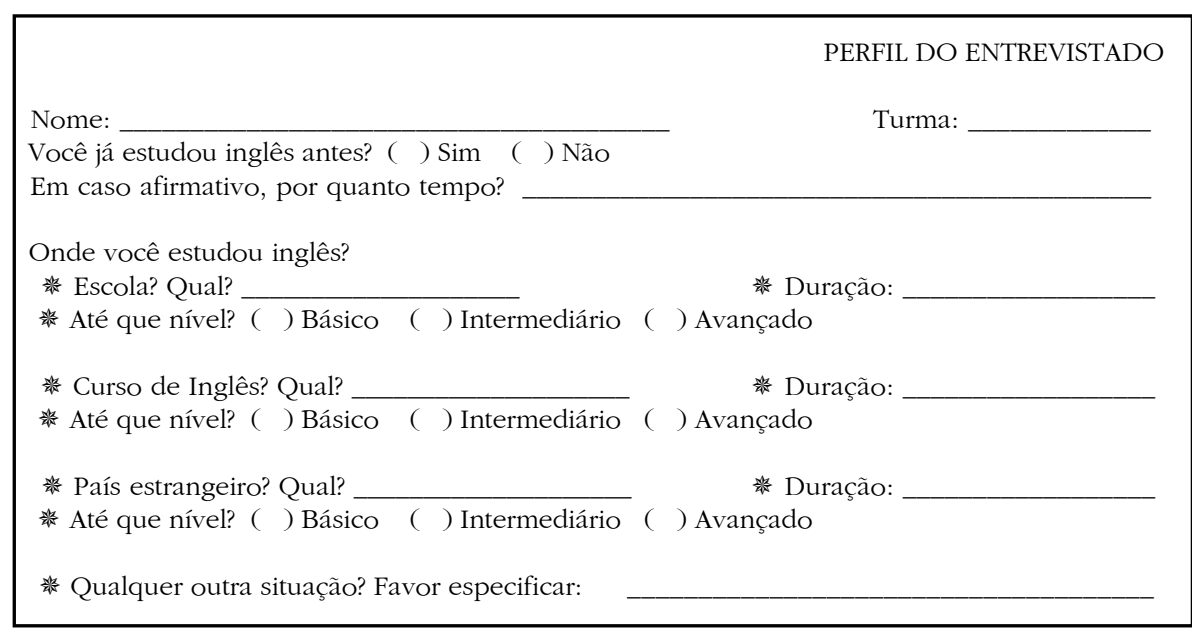

Reading Comprehension Activity

TRADUZA AS EXPRESSÕES NEGRITADAS DOS ENUNCIADOS ABAIXO:

1. A cold, sickening feeling came over me.

2. There had been a shooting at his son's school.

3. Mrs. Jackson-Lyons is a full time mother.

4. This unique image sensor significantly improves picture quality.

5. The completed DNA sequence is expected to give scientists unprecedented insights into the human body.

6. A Maryland neurologist filed a $\mathbf{\$ 8 0 0}$ million lawsuit against the no. 2 cellular phone maker.

7. It has a much cheaper price tag.

8. Two spacewalking astronauts fixed broken equipment tonight.

9. Free of surgical complications that may affect other methods, the patch delivers hormones directly through the skin.

10. Recent decades were characterized by an exaggerated sense of the nobility of untutored behavior. 